\title{
Effect of Co3O4 doping and sintering temperature on optical energy band gap properties in $\mathrm{Zn}-\mathrm{Bi}$-Ti-O varistor ceramics
}

\begin{abstract}
It is necessary to investigate the electronic states of ceramic based $\mathrm{ZnO}$ vasristor and effect of doped impurities at different concentration. Band gap (Eg) of the ceramic (99-x) mol\% $\mathrm{ZnO}+0.5 \mathrm{~mol} \% \mathrm{Bi} 2 \mathrm{O} 3+0.5 \mathrm{~mol} \% \mathrm{TiO} 2+\mathrm{xCo} 3 \mathrm{O} 4$ where $\mathrm{x}=0,0.2,0.4,0.6$ and $0.8 \mathrm{~mol} \%$, were determined using UV-Vis spectrophotometer. The samples were prepared via solid-state route and sintered at the sintering temperature at 1110,1140 and $1170{ }^{\circ} \mathrm{C}$ for 45 and $90 \mathrm{~min}$ in open air. At no doping of $\mathrm{Co} 3 \mathrm{O} 4$, the values of $\mathrm{Eg}$ are $2.991 \pm 0.001,2.989 \pm 0.001 \mathrm{eV}$ for 45 and 90 min sintering time; respectively. Eg was decreased to $2.368 \pm 0.002$ and $2.352 \pm$ $0.001 \mathrm{eV}$ at $0.8 \mathrm{~mol} \% \mathrm{Co} 3 \mathrm{O} 4$ for 45 and $90 \mathrm{~min}$ sintering time; respectively. XRD analysis indicates that two main phases existed at all concentrations which are $\mathrm{ZnO}$ and secondary phases, Bi12TiO20, Zn2Ti3O8, ZnCo2O4 and Co3Ti3O. Relative density decreases with the addition of $\mathrm{Co} 3 \mathrm{O} 4$ compared to that of undoped at all doping level. When $\mathrm{Co} 3 \mathrm{O} 4$ is added in the ceramics, relative density increases with the increase of doping level at both 45 and 90 min sintering time. The variation of sintering temperatures and XRD findings of steepness factor are correlated with the UV-Vis spectrophotometer results of based $\mathrm{ZnO}$ varistor doped with $\mathrm{Co} 3 \mathrm{O} 4$ due to the growth of interface states.
\end{abstract}

Keyword: Co3O4; Optical band gap energy; Ceramics; Zn-Bi-Ti-O 